\title{
Compressed valve in a calcified right ventricular outflow tract
}

\author{
Elżbieta Katarzyna Biernacka', Marcin Demkow², Mariusz Kuśmierczyk³, Witold Rużyłło \\ 1Department of Congenital Cardiac Defects, Institute of Cardiology, Warsaw, Poland \\ 2Department of Coronary and Structural Heart Diseases, Institute of Cardiology, Warsaw, Poland \\ 3Department of Cardiosurgery and Transplantology, Institute of Cardiology, Warsaw, Poland
}

Postep Kardiol Inter 2013; 9, 3 (33): 294-295

DOI: $10.5114 /$ pwki.2013.37513

Key words: transcatheter valve implantation, congenital heart disease.

A 14-year-old patient with the complex congenital heart defect of transposition of great arteries, ventricular septal defect and pulmonary stenosis, after the "réparation à l'etage ventriculaire" operation at the age of 3, was admitted to the hospital with critical pulmonary stenosis with a maximal right ventricle-pulmonary artery (RV-PA) gradient of $110 \mathrm{~mm} \mathrm{Hg}$. Transcatheter pulmonary valve implantation was performed in a stepwise manner: first, a metal stent LD Max S18-36 was implanted (BIB $22 \mathrm{~mm}$ ); subsequently a Melody valve was implanted with the $22 \mathrm{~mm}$ system and deployed with a high pressure balloon (Mullins $X 20 \mathrm{~mm}, 8 \mathrm{~atm}$ ). All was done with the access site via the right femoral vein (Figures 1-3). After the procedure, the pulmonary gradient measured invasively dropped to $23 \mathrm{~mm} \mathrm{Hg}$. The day after the valve was implanted, the RV-

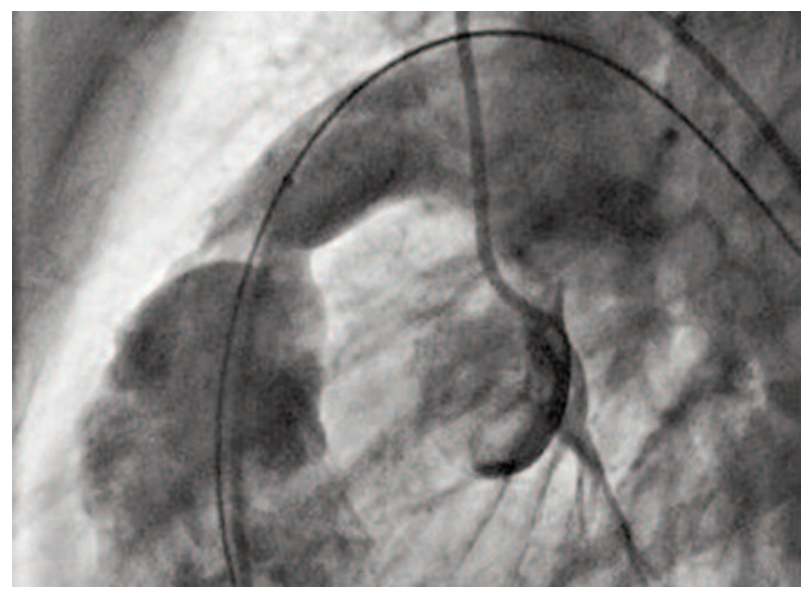

Fig. 1. Pulmonary angiogram - left lateral view; significant pulmonary incompetence and RVOT stenosis
PA gradient was 108-121 (mean 60) mm Hg. The chest $X$ ray showed a compressed valve-stent in the right ventricle outflow tract (RVOT) (Figures $4 \mathrm{~A}$ and B). The patient was scheduled for surgery. The pulmonary artery with the squeezed valve was removed (Figures 5) and the pulmonary homograft was successfully implanted. Extensive discentric RVOT calcifications may be connected with a risk of early valve compression. A staged procedure, with at least double-stent prestenting and delayed valve implantation, should be considered in this situation.

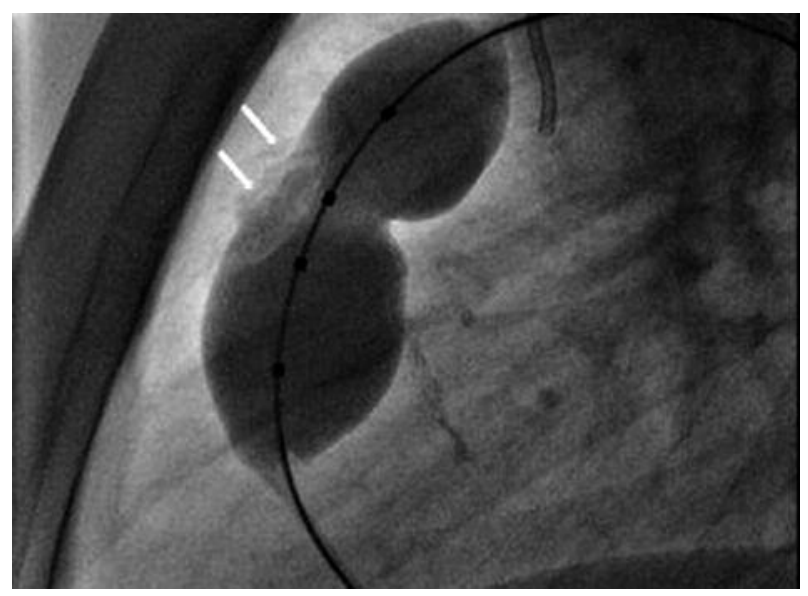

Fig. 2. Measurement of the size of the RVOT with the balloon - left lateral view; balloon waist marks the landing zone for the bare metal stent prestenting and the valve; the opacity in the part of the balloon located opposite to the posterior waist is caused by severe calcifications in the anterior wall of the RVOT (arrows)

\section{Corresponding author:}

Prof. Elżbieta Katarzyna Biernacka, Institute of Cardiology, 42 Alpejska St, 04-628 Warsaw, Poland, tel.: +48 223434634 , e-mail: k.biernacka@ikard.pl

Received: 1.07.2013, accepted: 12.07.2013. 


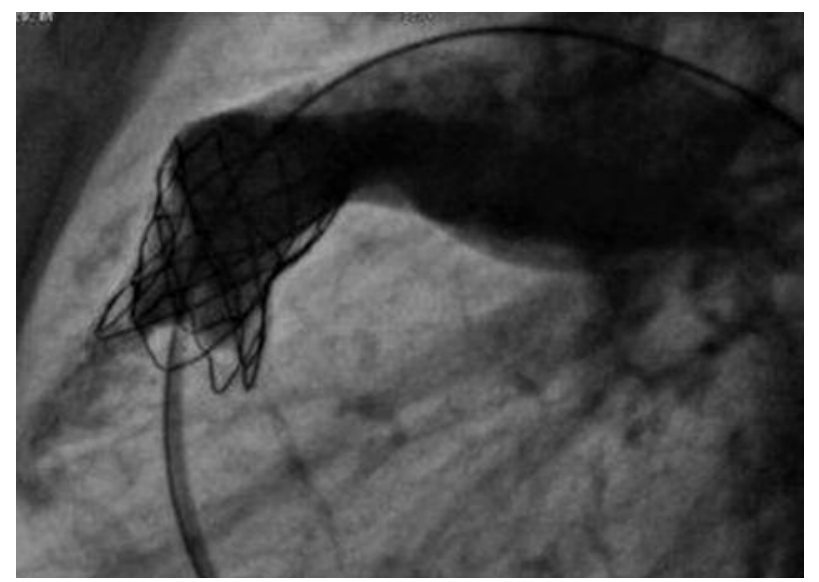

Fig. 3. Pulmonary angiogram, left lateral projection, immediate result after prestenting and Melody valve implantation: proper valve expansion, competent valve
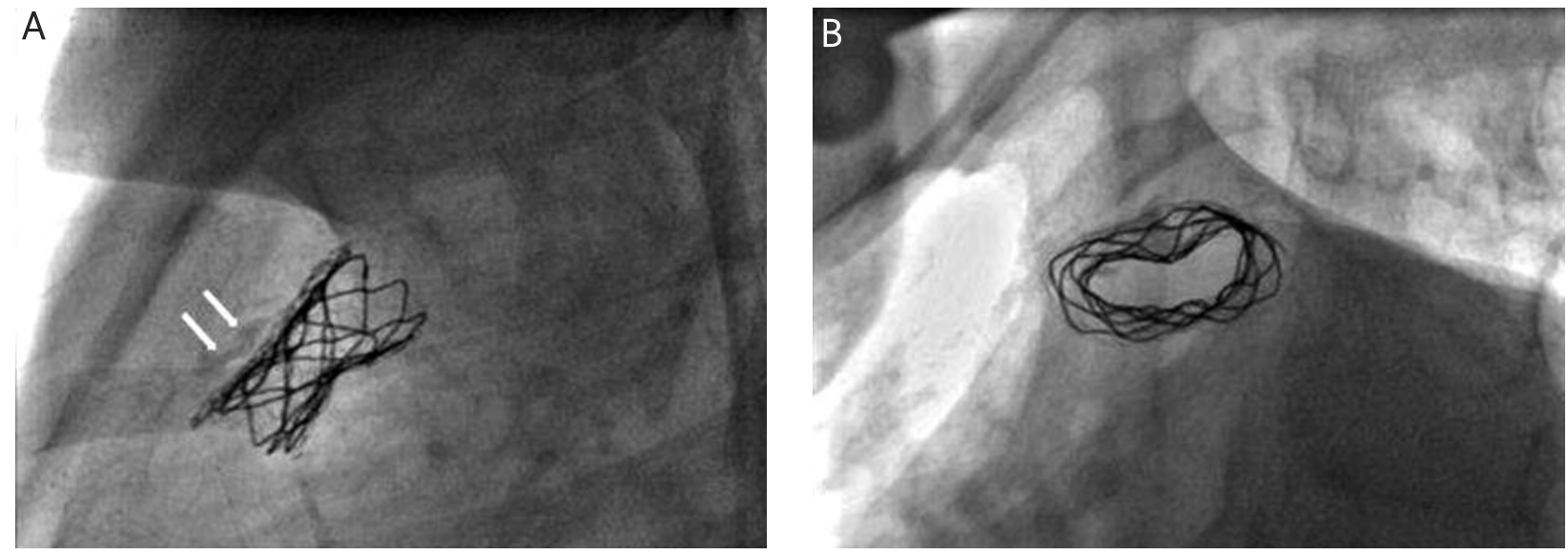

Fig. 4. The day after implantation. A - Left lateral projection, B - LAO + caudal projection: sqeezed valve-stent by severe calcifications of the anterior wall of the RVOT (arrows)

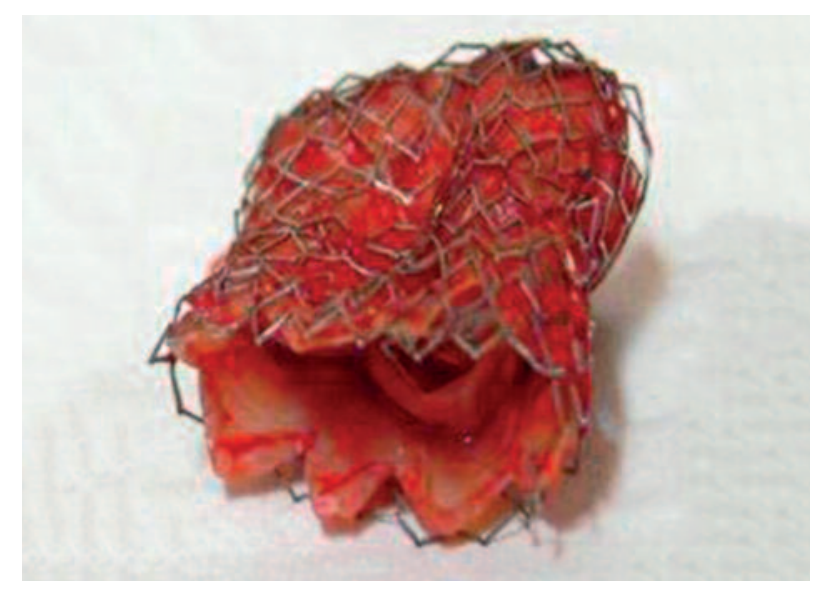

Fig. 5. Explanted compressed Melody valve 